\title{
XL. Examination of Cetine, ethal, oils of laurel turpentine, hyssop, and assafœtida
}

\section{Dr. John Stenhouse}

To cite this article: Dr. John Stenhouse (1842) XL. Examination of Cetine, ethal, oils of laurel turpentine, hyssop, and assafœtida , Philosophical Magazine Series 3, 20:131, 271-278, DOI: 10.1080/14786444208650568

To link to this article: http://dx.doi.org/10.1080/14786444208650568

册 Published online: 01 Jun 2009.

Submit your article to this journal $\lceil\pi$

Џ Article views: 2

Q View related articles $₫$ 
tained in the liquid as protoxide (an addition of a few drops of the sulphuret of ammonium answers the same purpose), and then thrown down by cyanide of potassium, and an excess of the latter added. The iron then dissolves immediately as ferrocyanide of potassium, while the oxide of chromium is left behind. In many cases the cyanide of potassium can be em. ployed to advantage in separating jron from alumina (little iron from much alumina), as the protoxide as well as the sulphuret of iron are so easily soluble in that salt, while alumina is perfectly insoluble. The cyanide of potassium well deserves to be studied as a general agent of separation. Unfortunately the composition of the numerous double compounds it forms with other cyanides is only imperfectly known, while their relation to mineral and vegetable acids is wholly unknown, so that the entire investigation must necessarily be repeated.

XL. Examination of Cetine, Ethal, Oils of Laurel Turpentine, Hyssop, and Assafotida. By Dr. John StenHOUSE*.

\section{Cetine.}

CHEVREUL gave the name of Cetine to spermaceti when rendered absolutely pure. The spermaceti of commerce always contains more or less of a yellowish oil, which it retains with great tenacity, and by which its melting point is greatly lowered. The best means of purifying spermaceti, is to treat it two or three times with boiling alcohol, in which, however, it is very slightly soluble, and then to subject it to nine or ten crystallizations in ether. These solutions and crystallizations must be repeated till the temperature at which the cetine solidifies reaches $120^{\circ} \mathrm{F}$. or $121^{\circ} \mathrm{F}$, when it may be regarded as perfectly pure.

The cetine which I subjected to analysis, was prepared in the manner just described, and solidifies at $121^{\circ} \mathrm{F}$. The following are the results:-

(1.) 0.236 gramme gave 0.6805 carbonic acid, and 0.2831 water.

(2.) 0.3198 gramme gave 0.9223 carbonic acid, and 0.378 water.

(3.) 0.2533 gramme gave 0.7286 carbonic acid, and 0.3008 water.

(4.) 0.2928 gramme gave 0.84 .68 carbonic acid, and 0.3476 water.

* Communicated by the Chemical Society, having been read November 17 th, 1841 . 


\begin{tabular}{|c|c|c|c|c|}
\hline & $\begin{array}{c}1 . \\
79 \cdot 72\end{array}$ & $\begin{array}{c}2 . \\
79 \cdot 74\end{array}$ & $\begin{array}{c}3 . \\
79 \cdot 53\end{array}$ & $\begin{array}{c}4 . \\
79 \cdot 96\end{array}$ \\
\hline & $13 \cdot 32$ & $13 \cdot 13$ & $13 \cdot 19$ & $13 \cdot 19$ \\
\hline \multirow{2}{*}{ Oxygen ..... } & 6.96 & $7 \cdot 13$ & $7 \cdot 28$ & 6.85 \\
\hline & & $00 \cdot 00$ & $100 \cdot 00$ & $100 \cdot 0$ \\
\hline
\end{tabular}

These analyses differ considerably from that of Chevreul, though I have repeated them with every attention to accuracy. Chevreul found

$$
\begin{array}{rr}
\text { Carbon . . . . } & 81 \cdot 660 \\
\text { Hydrogen . . . } & 12 \cdot 862 \\
\text { Oxygen . . . } & 5 \cdot 578
\end{array}
$$

It is needless, however, at present attempting to deduce any formula from these analyses, as the acids which spermaceti contains have not been accurately determined. Spermaceti is usually supposed to consist of margarate and oleate of ethal. From experiments, I have reason to think that one of them is margaric acid; but as spermaceti, when distilled, yields no trace of sebacic acid, there is every reason to conclude the other acid it contains, the quantity of which is extremely small, is certainly not the oleic acid.

In order to ascertain how far cetine differs in composition from ordinary spermaceti, I was induced to submit a portion of the latter also to analysis. The melting point of the crude spermaceti analysed was only $107^{\circ} \mathrm{F}$.

(1.) 0.3279 gave 0.9499 carbonic acid, and 0.3904 water.

(2.) 0.349 gave 1.0065 carbonic acid.

(3.) 0.3755 gave 1.0887 carbonic acid, and 0.4399 water.

$$
\begin{array}{cccc} 
& 1 . & 2 . & \multicolumn{1}{c}{3 .} \\
\text { Carbon. . . . } & 80 \cdot 10 & 79 \cdot 74 & 80 \cdot 16 \\
\text { Hydrogen . . } & 13.23 & & 13 \cdot 01 \\
\text { Oxygen . . . } & 6 \cdot 67 \\
\hline 100 \cdot 00 & & 6 \cdot 83 \\
& & 100 \cdot 00
\end{array}
$$

It is evident from these analyses, that the composition of crude spermaceti is precisely the same with that of the purest cetine. The small quantity of oil, therefore, which accompanies the former is probably isomeric with the more solid fat.

\section{Ethal.}

The ethal which I analysed was prepared by saponifying spermaceti with powdered potash. The saponification was twice repeated, in order that none of the spermaceti might escape decomposition. The lime-soap was then formed by precipitation with chloride of calcium. It was dried with a gentle heat and the ethal extracted by æther: alcoliol was found 
inadmissible, as a large quantity of the lime-soap was also dissolved by it. I also found it advantageous to mix the limesoap with a considerable quantity of pounded glass, as this prevented its adhering to the sides and bottom of the vessel when heated, and thus enabled the æther to act more equally on every part of the mass. The ethal first obtained was again boiled with milk of lime, again extracted with æther, and repeatedly crystallized. Its melting point was $119^{\circ} \mathrm{F}$.

(1.) 0.5307 gave 1.519 carbonic acid, and 0.665 water.

(2.) 0.2881 gave 0.8295 carbonic acid, and 0.361 water.

(3.) 0.302 gave 0.8645 carbonic acid, and 0.383 water.

\begin{tabular}{|c|c|c|c|}
\hline & 1. & 2. & 3. \\
\hline Carb & $79 \cdot 14$ & $79 \cdot 61$ & $79 \cdot 15$ \\
\hline en . . & 13.92 & $13 \cdot 02$ & 14.08 \\
\hline $\mathbf{x}$ & $6 \cdot 94$ & 6.47 & 6.77 \\
\hline & $100 \cdot 00$ & $00 \cdot 00$ & 00 \\
\hline
\end{tabular}

These analyses agree very closely with the calculated numbers, and with the analyses of Chevreul and Dumas.

$$
\begin{aligned}
& \text { Calculated numbers. } \\
& \text { Atorns. Per cent. } \\
& \text { Carbon ...... } 32=79 \cdot 69 \\
& \text { Hydrogen. . . . . 34 }=13.82 \\
& \text { Oxygen ..... } 2=6.51
\end{aligned}
$$

Laurel Turpentine.

For some years past, an essential oil, to which the name of Laurel has been improperly given, has been imported in considerable quantities from Demerara and some other parts of South America. It has been successfully employed as an external application for the cure of rheumatism. It is also an excellent solvent for caoutchouc, as it dissolves that substance very readily, and leaves it in a firmer and less altered state than either naphtha or oil of turpentine. Its comparatively high price, however, $1 s$. per oz., precludes its employment for this purpose. The botanical nature of the tree which produces it is unknown. The Spaniards call the tree "acaita de sassefras." I think it probable that it is a species of pine. 'These trees are not very abundant, but the quantity of oil they contain is exceedingly great. It runs out abundantly when incisions are made near the root of the tree, and it also not unfrequently exudes spontaneously. The oil as it occurs in commerce is transparent, but of a slightly yellow colour, owing to its containing a little resinous matter, which is easily removed by distilling it with water. The smell of this oil reminds one of that of turpentine, but it is much more agreeable, and approaches more nearly that of oil of lemons; its specific 
gravity is 0.864 .5 at $56^{\circ} \mathrm{F}$. Oil of laurel is accompanied with a volatile acid, the quantity of which, however, is extremely small. When this acid is boiled with nitrate of silver, the oxide is reduced to the metallic state. The acid is probably therefore the Formic.

To prepare the oil for analysis it was distilled with water to remove the resin it contained, and then rendered anhydrous by fused chloride of calcium. When rectified on the oil-bath, it began to boil at $301^{\circ} \mathrm{F}$, but the boiling point gradually rose to $325^{\circ} \mathrm{F}$. It was then transparent and colourless. The first portion that distilled over was set aside, but the second and third, which contained nearly an ounce each, were separately collected, and subjected to analysis with oxide of copper.

(1.) 0.2677 gramme, boiling at $301^{\circ} \mathrm{F}$, gave 0.857 carbonic acid, and 0.279 water.

(2.) 0.2839 gramme, boiling at $325^{\circ} \mathrm{F}$., gave $0.9062 \mathrm{car}-$ bonic acid, and 0.2956 water.

1.

2. Calculated numbers.

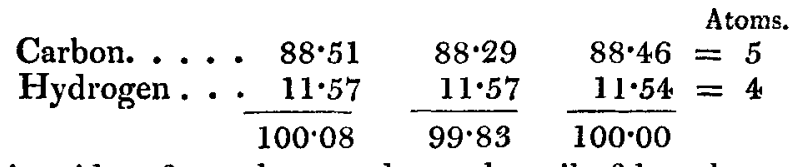

It is evident from these analyses, that oil of laurel consists of two or more isomeric oils belonging to the numerous tribe of carburetted hydrogens of which oil of turpentine is the type, containing carbon and hydrogen in the proportion of 5 to 4 . The action of the reagents on oil of laurel is so similar to that on oil of turpentine as to render details unnecessary. The reason which has induced me to change the name of oil of laurel to that of laurel turpentine is, that there are two oils of laurel already, one fixed and the other volatile, with which it might otherwise be easily confounded.

\section{Oil of Hyssop.}

The essential oil of hyssop is easily obtained by the usual process of distilling the plant with water. The quantity which it yields is pretty considerable. The oil has the smell of the plant, and its taste, like that of the other essential oils, is very pungent. When fresh it is transparent and colourless; but when kept some time, especially if the air is not carefully excluded, it becomes yellowish, owing to the formation of a small quantity of resin. Oil of hyssop is lighter than water and quite neutral; its boiling point is not at all fixed; it begins to boil at $288^{\circ} \mathrm{F}$, but the boiling gradually rises till it reaches $325^{\circ}$, soon after which it begins to pass over coloured : 
it is evidently a mixture of several oils. In order to determine this more certainly, the anhydrous oil was rectified, and the product of its distillation at different temperatures collected separately and subjected to analysis. The following are the results :-

(1.) 0.289 gramme, boiling at $288^{\circ} \mathrm{F}$, gave 0.8794 carbonic acid, and 0.2875 water.

(2.) 0.3022 gramme, boiling at $299^{\circ} \mathrm{F}$., gave 0.8885 carbonic acid, and 0.298 water.

(3.) 0.2838 gramme, boiling at $335^{\circ} \mathrm{F}$., gave 0.8243 carbonic acid, and 0.2671 water.

1.

$\begin{array}{lr}\text { Carbon...... } & 84.13 \\ \text { Hydrogen. . } & 11.05 \\ \text { Oxygen. . . . } & \frac{4.82}{100.00}\end{array}$
2.

$81 \cdot 29$

$10 \cdot 95$

$7 \cdot 76$

$\overline{100 \cdot 00}$
3.

$80 \cdot 31$

$10 \cdot 45$

$\frac{9 \cdot 24}{100 \cdot 00}$

It will at once be perceived from these results, that the portion of the oil richest in carbon and bydrogen distils over at a comparatively low temperature, and that as the quantity of oxygen in the oil increases, its boiling point rises. This is what usually takes place with oils which consist of a mixture of a carburetted hydrogen, and more or less oxygenated oils. I was induced therefore to try if these different oils could be separated by treating them with fused potash--the method so successfully employed by Messrs. Gerhardt and Cahours with oil of cumin, and which promises to be extremely useful in the investigation of this class of bodies. The oil of hyssop was dropped upon the potash through a capillary opening in the tubes of a retort. As soon as the oil came in contact with the melted potash, the greater portion of it was converted into a brownish resin, but a part of it passed into the receiver. This portion was again subjected to the action of the potash, when still more of it was converted into resin. What distilled over was considerably different in taste and smell from ordinary oil of hyssop. When subjected to analysis,

0.3047 gramme gave 0.955 carbonic acid, and 0.313 water, $=$

$$
\begin{array}{rr}
\text { Carbon . . . . . } & 86.65 \\
\text { Hydrogen. . . . } & 11.41 \\
\text { Oxygen . . . } & \frac{1.94}{100.00}
\end{array}
$$

It is evident, therefore, that I did not succeed in converting oil of hyssop into a pure carburetted hydrogen, though the quantity of the oxygenated oil was considerably diminished.

$$
\text { Oil of Assafcetida. }
$$

It is to this oil that assafœetida owes its highly offensive 
smell. The quantity of oil which the resin yields, varies according to its freshness. A pound of the resin generally yields about one-third of an ounce of oil, which is obtained by distillation with water in the usual way. It is advisable to mix the resin with pounded glass, as this prevents the resin from adhering to the bottom of the retort, and both hinders it from burning and diminishes the violence of the succussions with which the distillation would otherwise be attended. The oil has usually a slightly yellowish tint: its specific gravity is 0.9428 at $60^{\circ} \mathrm{F}$.; its taste is first mild and then acrid. When exposed for some time to the air it oxidizes, and a resinous matter forms in it. In order to prepare it for analysis, the oil which had been twice distilled with water to remove all the resin was rectified over chloride of calcium on the oil-bath. Its boiling point is by no means constant; it began to boil at $325^{\circ} \mathrm{F}$, and continued to rise till it reached $370^{\circ} \mathrm{F}$. The receiver was changed three times during the distillation, and the products separately collected and analysed. The presence of sulphur in oil of assafcetida was first noticed by Zeise. It differs from oil of mustard, by containing no nitrogen. The carbon and hydrogen were estimated by analysis with oxide of copper, and the sulphur was determined by passing the oil in vapour over a mixture of nitre and carbonate of baryta at a red heat. The following are the results :-

(1.) Analysis of 1 st quantity, 0.2967 oil, boiling at $325^{\circ} \mathrm{F}$., gave 0.710 carbonic acid, and 0.2625 water.

(2.) Analysis of 1 st quantity, 0.2915 , gave 0.6935 carbonic acid, and 0.253 water.

Per cent.

0.382 oil gave 0.635 sulphate of baryta $=22.93$ sulphur.

0.391 oil gave 0.639 sulphate of baryta $=22.54$ sulphur.

1.2 . 2.

$$
\begin{array}{lrr}
\text { Carbon ... . } & 66 \cdot 16 & 65 \cdot 78 \\
\text { Hydrogen . } & 9 \cdot 83 & 9 \cdot 64 \\
\text { Sulphur . . } & 22.93 & 22 \cdot 54 \\
\text { Oxygen . . } & \frac{1.08}{100 \cdot 00} & \frac{2 \cdot 04}{100 \cdot 00}
\end{array}
$$

(1.) Analysis of 2nd quantity of oil, boiling at $341^{\circ} \mathrm{F}$., 0.2312 gave 0.523 carbonic acid, and 0.1967 water.

(2.) Analysis of 2 nd quantity, 0.2728 gave 0.6177 carbonic acid, and 0.2224 water.

(3.) Analysis of 2 nd quantity, 0.2889 gave 0.6461 carbonic acid, and 0.2447 water.

0.413 oil gave 0.601 sulphate of baryta $=20.12$ per cent. sưlphur.

0.421 gave 0.610 sulphate of baryta $=19.99$ per cent. sulphur. 
Dr. Stenhouse on Oil of Assafoetida, \&c.

1.

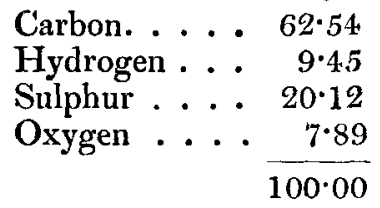

2.

$62 \cdot 60$

$9 \cdot 05$

$19 \cdot 99$

$8 \cdot 36$

$100 \cdot 00$
3.

$61 \cdot 83$

$9 \cdot 4,1$

(1.) Analysis of 3rd quantity of oil, boiling at $370^{\circ} \mathrm{F}$., 0.3036 gave 0.64 .15 carbonic acid, and 0.2493 water.

(2.) Analysis of 3rd quantity of oil, 0.2947 gave 0.6185 carbonic acid, and 0.2413 water. phur.

0.344 gave 0.421 sulphate of baryta $=16.88$ per cent. sulphur.

0.382 gave 0.436 sulphate of baryta $=15^{\circ} 74$ per cent. sul-

1.

$\begin{array}{lr}\text { Carbon. . . . . } & 58 \cdot 42 \\ \text { Hydrogen . . } & 9 \cdot 12 \\ \text { Sulphur . . . } & 16 \cdot 88 \\ \text { Oxygen } . . . & \frac{15 \cdot 58}{100 \cdot 00}\end{array}$
2.

$58 \cdot 03$

$9 \cdot 09$

$15 \cdot 74$

$17 \cdot 14$

It is evident from these results, that oil of assafœetida is a mixture of various oils, one or more of which consist probably only of carbon, hydrogen and sulphur, with other oils containing more or less oxygen. The less oxygenated portion is the most volatile. It is therefore unnecessary to attempt to deduce any formula from these analyses. Though oil of assafœida was twice treated with fused potash in the same manner as oil of hyssop, the greater portion of the sulphur was removed, but $\tilde{I}$ could not succeed in getting rid of the whole. The greater portion of the oil was converted into a blackish resin. This resinous matter is soluble in alkali, from which it is precipitated by acids. It is not in the least degree crystalline. The action of reagents on oil of assafœetida was as follows :-salts of silver, lead and protoxide of mercury gave black precipitates. When brought in contact with peroxide of mercury, heat was evolved, and a part of the oxide was converted into a greenish yellow mass, which was insoluble in water. A very small portion of the oil was acted on however. Corrosive sublimate immediately produced a copious flocculent white precipitate. It was insoluble in water, alcohol and xther. It was soluble in nitric acid, and when boiled with solution of potash, the mercury was precipitated in the state of protoxide. Oil of assafoetida does not combine with ammonia. It is very little acted on either by aqueous or alcoholic solntions of potash. Nitric acid acts on this oil with 
great energy, and the evolution of deutoxide of azote. It is converted into a resin, and on adding a salt of baryta an abundant precipitate of sulphate of baryta is obtained. Sulphuric acid first reddens, and with the assistance of heat, chars it. It dissolves iodine readily, but without explosion Glasgow, 14th October, 1841.

XLI. On the Constitution of the Atmosphere. By James Ivory, K.H., M.A., Hon. M.R.I.A., Instit. Reg. Sc. Paris, et Reg. Soc. Götting. Corresp.*

I N the last Number of this Journal (p. 197) I assumed that the atmosphere is composed solely of oxygen and azote: but besides these gases, it is found to contain a small proportion of carbonic acid gas, the quantity of which has been in some degree appreciated. It may not therefore be improper briefly to resume the subject, in order to take in all the constituent parts of the atmosphere, as far as they are known, leaving out the consideration of aqueous vapour, which requires a separate discussion. Suppose three several portions of oxygen, azote, and carbonic acid gas, their common temperature being $\theta$, and their pressures, densities, and volumes being represented respectively by $p, \rho, v, p^{\prime}, \rho^{\prime}, v^{\prime}, p^{\prime \prime}, \rho^{\prime \prime}, v^{\prime \prime}$; and let the three gases be confined in an envelop, the volume of which is $V=v+v^{\prime}+v^{\prime \prime}$. According to the theory of mixed gases, as explained in this Journal for February last (p. 81), each of the three gases will be uniformly diffused through the envelop, and the elasticity of the mixture, resulting from the mutual action of the three elasticities, will be

$$
p \cdot \frac{v}{\mathrm{~V}}+p^{\prime} \cdot \frac{v^{\prime}}{\mathrm{V}^{-}}+p^{\prime \prime} \cdot \frac{v^{\prime \prime}}{\overline{\mathrm{V}}}:
$$

and if we suppose $p=p^{\prime}=p^{\prime \prime}$, the same elasticity will be simply $p$. Let $\mathrm{R}$ be the density of atmospheric air, the pressure being $p$ and the temperature $\theta$ : then the four densities $\mathrm{R}, \rho, \rho^{\prime}, \rho^{\prime \prime}$, will be proportional to the numbers 1, 1.1057, $0.972,1.52 \dagger$, for which we may write $1, A, A^{\prime}, A^{\prime \prime}$ : so that we shall have

$$
\begin{aligned}
& \rho=\mathbf{A} \cdot \mathbf{R}, \\
& \rho^{\prime}=\mathbf{A}^{\prime} \cdot \mathbf{R}, \\
& \rho^{\prime \prime}=\mathbf{A}^{\prime \prime} \cdot \mathrm{R}:
\end{aligned}
$$

and if we multiply the densities by the respective volumes, and add the products, there will result

$$
v \rho+v^{\prime} \rho^{\prime}+v^{\prime \prime} \rho^{\prime \prime}=\left(\mathrm{A} v+\mathrm{A}^{\prime} v^{\prime}+\mathrm{A}^{\prime \prime} v^{\prime \prime}\right) \mathbf{R} .
$$

* Communicated by the Author.

† The more exact number is 1.5196.-Biot, Précis de Phys. 